\title{
2 Carrageenan-based superabsorbent biopolymers mitigate 3 autogenous shrinkage in ordinary portland cement
}

\author{
4 Anastasia N. Aday • Jorge Osio-Norgaard • Kyle E. O. Foster • Wil V. Srubar III
}

5 Received: 8 December 2017/Accepted: 13 February 2018

6 (C) RILEM 2018

7 Abstract We report the synthesis and characteriza8 tion of biobased superabsorbent copolymers from $\kappa$ 9 carrageenan and poly(acrylic acid) that mitigate 10 autogenous shrinkage in ordinary portland cement 11 paste. Synthesized via free radical graft polymeriza12 tion, the biobased superabsorbent polymers (SAPs) 13 were characterized with regard to their thermochem14 ical properties and swelling behavior in both aqueous 17 Q1 and ionic solutions. The biobased SAPs were incor16 porated into cement paste to investigate their ability to 17 mitigate autogenous shrinkage cracking in high-per18 formance concrete. Results demonstrate that the 19 biobased SAPs absorb up to 438 and 94 [g/g] (by 20 mass) in aqueous and ionic solutions, respectively, 21 after $24 \mathrm{~h}$. Furthermore, the biobased SAPs were 22 successful in mitigating shrinkage in low water-to23 cement ratio pastes. While the control paste exhibited 24 negative strain and ultimate shrinkage cracking, the 25 samples containing biobased SAP experienced net$2 \longdiv { \mathrm { AQ } _ { 2 } 2 }$ positive expansion during cement hydration.

\footnotetext{
A1 A. N. Aday - K. E. O. Foster · W. V. Srubar III ( $₫)$

A2 Materials Science and Engineering Program, University

A3 of Colorado Boulder, ECOT 441 UCB 428, Boulder,

A4 CO 80309-0428, USA

A5 e-mail: wsrubar@colorado.edu

A6 J. Osio-Norgaard - W. V. Srubar III

A7 Department of Civil, Environmental, and Architectural

A8 Engineering, University of Colorado Boulder, ECOT 441

A9 UCB 428, Boulder, CO 80309-0428, USA
}

Keywords Superabsorbent polymer (SAP) - Internal curing $\cdot$ Biopolymers $\cdot$ Cement $\cdot$ Autogenous shrinkage

1 Introduction

1.1 Superabsorbent polymers

Over the past few decades, the use of superabsorbent polymers (SAPs) in cement-based materials has increased due to their proven ability to improve initial and long-term performance. SAPs have been shown to mitigate early-age autogenous shrinkage [1, 2], increase freeze-thaw resistance [3-5], and, more recently, to impart self-healing characteristics $[6,7]$ to ordinary portland cement (OPC) concrete. While a majority of these studies employ commercially available SAPs, some studies have reported the synthesis and chemical characterization of novel SAPs [8-10] and their interaction with cement-based materials.

SAPs are crosslinked networks of ultra-hydrophilic polymers that can absorb up to $100,000 \%$ of their dry weight in aqueous solutions [11]. The ability of the polymer to absorb fluids is attributed to the abundance of hydrophilic functional groups present on the polymer backbone, while the crosslinks in SAP networks render the polymer insoluble $[12,13]$. While commonplace SAPs have been synthesized using ionic

\begin{tabular}{|l|lll|} 
Journal : Medium 11527 & Dispatch : 15-2-2018 & Pages : 13 \\
Article No. : $\mathbf{1 1 6 4}$ & $\square$ LE & $\square$ TYPESET \\
MS Code : MAAS-D-17-01472 & $\checkmark \mathrm{CP}$ & $\checkmark$ DISK \\
\hline
\end{tabular}


acrylate/acrylamide homopolymers, the use of superabsorbent hydrophilic biopolymers, such as alginates, celluloses, and carrageenans [14], as biological precursors for SAPs has been largely unexplored for applications in cementitious materials.

\subsection{Carrageenan}

Carrageenans are a class of linear, hydrophilic polysaccharides present in various species of red seaweeds in the class, Rhodophyceae. Carrageenans are classified using Greek prefixes, such as $\kappa, \imath$, and $\lambda$. All $\kappa, l$, and $\lambda$ carrageenans consist primarily of sulfated esters (i.e., D-galactose and 3,6-anhydro-Dgalactose copolymers) with $\alpha-1,3$ and $\beta-1,4$ linkages [15]. Carrageenans are typically extracted through an alkaline process, resulting in a negatively charged polymer with a corresponding cation of either $\mathrm{Na}^{+}$or $\mathrm{K}^{+}[16,17]$. Carrageenans are categorized per the location and number of these sulfate ester groups, with $\kappa, l$, and $\lambda$ carrageenans having one, two, and three groups, respectively [18]. Of these carrageenans, $\kappa-$ carrageenan (Fig. 1) and i-carrageenan both swell and form gels in the presence of $\mathrm{K}^{+}$and $\mathrm{Ca}^{2+}$ ions [15]. While the gelling behavior of $\kappa$-carrageenan is complex, the gels have a double helix conformation in the cooled state, creating a strong and brittle gel with thermoreversible gelling properties in water $[19,20]$.

\subsection{Autogenous shrinkage}

Autogenous shrinkage (AS) is a ubiquitous early-age issue with concrete, particularly high-performance (i.e., high strength, low water-to-cement (w/c) ratio) pastes, mortars, and concrete [21-23]. AS is a phenomenon caused by self-desiccation of cement paste as it pulls water from the surface of calcium silicate hydrate $(\mathrm{C}-\mathrm{S}-\mathrm{H})$ gel to further the hydration of anhydrous cement [21]. Self-desiccation creates internal stresses leading to cracking in the paste, which can

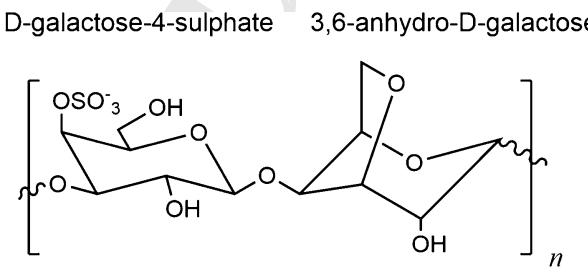

Fig. 1 Chemical structure of $\kappa$-carrageenan [17] diminish mechanical properties and long-term durability [21].

Internal curing methodologies have been proposed to address AS [24]. Internal curing approaches have utilized SAPs, pre-wetted lightweight aggregates, or other admixtures to provide additional entrained water to anhydrous cement. The additional water reduces early-age compressive strength without compromising overall strength [23, 25]. For internal curing using SAPs, dry SAPs are mixed in with the cement and absorb additional water stipulated by the mix design. As the initially hydrated cement begins to undergo self-desiccation, these SAPs release absorbed water to compensate for moisture loss, thus mitigating shrinkage and potential crack formation. Ongoing work has recently established procedural methods that describe characterization of SAP sorption properties prior to usage in cement-based materials, thus aiding in the understanding of how SAPs can be utilized to mitigate AS $[26,27]$.

1.4 Scope of work

The objective of this work was to synthesize and characterize a superabsorbent, biobased copolymer from $\kappa$-carrageenan and poly(acrylic acid), adhering to green chemistry practices with an aqueous, free radical copolymerization technique. Biobased SAPs are synthesized herein from an acrylic acid monomer covalently crosslinked with a multivalent agent $\left(N, N^{\prime}-\right.$ methylenebisacrylamide) in a free radical polymerization that grafts the poly(acrylic acid) chain to $\mathrm{\kappa}$ carrageenan. The polymerization process in this study proceeds in an aqueous media due to the solubility of the biopolymer, monomer, and crosslinking agent. After thermochemical and physical swelling characterization, the resulting synthesized SAPs were tested as a water-retention additive in cement paste to evaluate their effectiveness in reducing autogenous shrinkage.

$\kappa$-Carrageenan ( $\mathrm{C}$ ), acrylic acid (AA), $N, N^{\prime}$ methylenbisacrylamide (MBA), ammonium persulfate (APS), and sodium hydroxide $(\mathrm{NaOH})$ were

\begin{tabular}{|l|lll|}
\hline & Journal : Medium 11527 & Dispatch : 15-2-2018 & Pages : 13 \\
Article No. : $\mathbf{1 1 6 4}$ & $\square$ LE & $\square$ TYPESET \\
& MS Code : MAAS-D-17-01472 & $\checkmark \mathrm{CP}$ & $\checkmark$ DISK \\
\hline
\end{tabular}


obtained from Sigma-Aldrich and used without further purification. A stock solution of $1 \mathrm{M} \mathrm{NaOH}$ was prepared. The cement used in this study was a commercially available Type I/II OPC (Quikrete ${ }^{\circledR}$ ) that complies with ASTM C150. See Table 1 for chemical composition of OPC obtained via inductively coupled plasma optical emission spectroscopy (ICP-OES).

\subsection{Methods}

\subsubsection{Biobased SAP synthesis}

The biobased SAPs were synthesized using free radical graft polymerization under ambient conditions. Deionized water was added to a beaker and heated to $70{ }^{\circ} \mathrm{C}$ in an oil bath. $\kappa \mathrm{C}$ was continuously added and stirred with a stir bar at $300 \mathrm{rpm}$ until a homogeneous solution was achieved. To the solution, AA was added followed by MBA with continuous stirring. The watersoluble initiator, APS, was added to the solution and stirred until the viscosity increased to the point of gel formation. The gel was then removed from the oil bath and allowed to cool under ambient conditions. Upon cooling, a $1 \mathrm{M}$ solution of $\mathrm{NaOH}$ was added to the gel to neutralize the carboxylic acid groups and handstirred until the gel had absorbed the solution. The gel was then transferred to a beaker of methanol to dewater for $1 \mathrm{~h}$. The methanol was decanted and fresh methanol was added to the gel to dewater for $24 \mathrm{~h}$. After dewatering, the gel was allowed to dry in an oven $\left(20 \% \pm 5 \% \mathrm{RH}, 40{ }^{\circ} \mathrm{C} \pm 5{ }^{\circ} \mathrm{C}\right)$. Dried gel was then ground into a powder using a mechanical grinder and sieved to a $125-250 \mu \mathrm{m}$ particle size. Dried samples were then stored away from heat, light, and moisture. To minimize variables in the synthesis, only the amount of AA monomer was varied in order to investigate the swelling behavior at various AA concentrations. Figure 2 illustrates a generalized mechanism of the grafting and crosslinking of $\kappa \mathrm{C}$ onto acrylic acid. The APS initiator thermally decomposes to generate a sulfate anion-radical, where the radical abstracts hydrogen from the hydroxyl group of $\kappa \mathrm{C}$ forming an alkoxy radical (APS- $\kappa \mathrm{C}$ ). Active centers on the APS $-\kappa \mathrm{C}$ redox system then radically initiate the polymerization of AA resulting in a graft copolymer. See Table 2 for a list of sample formulations.

\subsubsection{Physical and chemical characterization}

2.2.2.1 Differential scanning calorimetry Thermal data for samples dried for at least 3 days were collected using a TA Instruments Q2000 Differential Scanning Calorimeter (DSC) in a $\mathrm{N}_{2}$ environment using a purge rate of $50 \mathrm{~mL} / \mathrm{min}$. $6 \mathrm{mg}$ samples of SAP were placed in hermetically sealed aluminum pans. The samples were first equilibrated to $15^{\circ} \mathrm{C}$ followed by heating at a rate of $10{ }^{\circ} \mathrm{C} / \mathrm{min}$ to $250{ }^{\circ} \mathrm{C}$. The samples were then cooled at a rate of $10{ }^{\circ} \mathrm{C} / \mathrm{min}$ to $0{ }^{\circ} \mathrm{C}$ and then heated again to $250{ }^{\circ} \mathrm{C}$ at a rate of $10^{\circ} \mathrm{C} / \mathrm{min}$. Enthalpy calculations and transition temperatures were analyzed using Universal Analysis software (TA Instruments).

2.2.2.2 Thermogravimetric analysis Thermogravimetric analysis (TGA) of dried SAPs was performed using a TA Q50 TGA. All samples were tested under nitrogen gas. All samples underwent the same sequence of thermal processing: equilibration at $25^{\circ} \mathrm{C}$ for $1 \mathrm{~min}$, followed by heating at a rate of $10^{\circ} \mathrm{C} / \mathrm{min}$ to $900{ }^{\circ} \mathrm{C}$ where they were held for $5 \mathrm{~min}$, then cooled rapidly back to $25^{\circ} \mathrm{C}$. All weight-percent traces were differentiated with respect to time in Origin 2017 analysis software to emphasize major decomposition events of each material.

\subsubsection{Fourier transform infrared spec-} troscopy Fourier Transform Infrared Spectroscopy (FTIR) was conducted using a Cary 630 equipped with an Attenuated Total Reflection (ATR) accessory. 40 spectra were collected from 4000 to $500 \mathrm{~cm}^{-1}$ at a resolution of $1 \mathrm{~cm}^{-1}$ for each sample. All spectra were processed using Origin 2017 analysis software.

Table 1 Chemical composition of Type I/II OPC

\begin{tabular}{lllllllll}
\hline Chemical composition (wt\%) & $\mathrm{CaO}$ & $\mathrm{SiO}_{2}$ & $\mathrm{Al}_{2} \mathrm{O}_{3}$ & $\mathrm{Fe}_{2} \mathrm{O}_{3}$ & $\mathrm{~K}_{2} \mathrm{O}$ & $\mathrm{Na}_{2} \mathrm{O}$ & $\mathrm{MgO}$ & Other \\
\hline Type I/II Cement & 73.7 & 12 & 7 & 4.1 & 0.9 & 0.3 & 0.0003 & 2 \\
\hline
\end{tabular}

\begin{tabular}{|l|lll|}
\hline & Journal : Medium 11527 & Dispatch : 15-2-2018 & Pages : 13 \\
Article No. : $\mathbf{1 1 6 4}$ & $\square$ LE & $\square$ TYPESET \\
& MS Code : MAAS-D-17-01472 & $\checkmark \mathrm{CP}$ & $\checkmark$ DISK \\
\hline
\end{tabular}




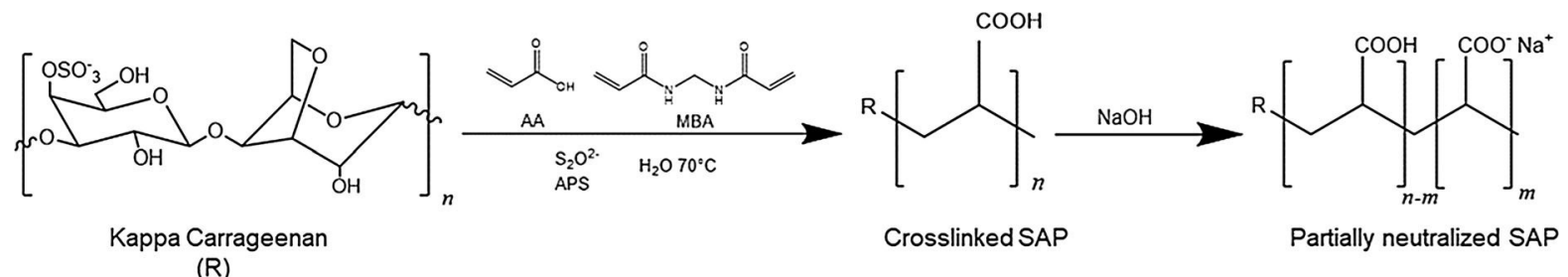

Fig. 2 Generalized mechanism of the synthesis of biobased SAP

Table 2 Biobased SAP sample compositions

\begin{tabular}{lllll}
\hline Sample & $\kappa \mathrm{C}(\mathrm{g})$ & AA $(\mathrm{mL})$ & MBA $(\mathrm{g})$ & APS $(\mathrm{g})$ \\
\hline SAP A & 1.00 & 3.5 & 0.1 & 0.2 \\
SAP B & 1.00 & 2.5 & 0.1 & 0.2
\end{tabular}

208

209

210

211

212

213

214

215

216

\subsubsection{Scanning electron microscopy Scanning} electron microscopy (SEM, JEOL JSM-6840LV) was performed using an accelerating voltage of $15 \mathrm{kV}$ to confirm particle size and analyze polymer morphology. Non-powdered and powdered samples were attached to aluminum stubs using carbon tape and then sputter-coated with $\mathrm{Au}$ (Cressington 108auto) for $20-25 \mathrm{~s}$ at $\mathrm{mA}(\sim 3.5-4.0 \mathrm{~nm})$ in an Ar-rich environment.

2.2.2.5 Physical swelling All dried samples were weighed and added to a pre-wetted, $150 \mu \mathrm{m}$ mesh bag, immersed in deionized water, tap water, $0.1 \mathrm{M} \mathrm{NaOH}$ solution, and a synthetic pore solution at room temperature, and allowed to swell in time intervals of $1,3,5,10,15,30,60,120 \mathrm{~min}$, and $24 \mathrm{~h}$. During the swelling tests, no SAP particle loss to the solution was observed. A synthetic concrete pore solution ( $\mathrm{pH}$ 13.4) was synthesized to mimic the solution chemistry that is typically observed during OPC hydration reactions. The solution was saturated with $\mathrm{Ca}(\mathrm{OH})_{2}, 11.22 \mathrm{~g} / \mathrm{L}$ $\mathrm{KOH}, 4.0 \mathrm{~g} / \mathrm{L} \mathrm{NaOH}, 13.77 \mathrm{~g} / \mathrm{L} \mathrm{Ca}\left(\mathrm{SO}_{2}\right)_{4}$ were added to $1 \mathrm{~L}$ of deionized water, where the measured ion composition can be obtained from Ghods et al. [28]. Swelling ratio $(Q)$ was measured by removing the bag from the solution and excess solution was allowed to drain from the bag. After correcting for solution absorbed by the bag, $Q$ was calculated according to:

$Q\left(\frac{g}{g}\right)=\frac{w_{\text {wet }}-w_{\text {dry }}}{w_{\text {dry }}}$

where $w_{\text {wet }}$ and $w_{\text {dry }}$ are the weights of the moistened polymer and dry polymer, respectively.

\subsubsection{Autogenous shrinkage}

2.2.3.1 Cement paste preparation Similar to other studies [29-31], three samples of cement paste with a base w/c ratio of 0.30 and an entrained water content of 0.05 were prepared. The entrained water amount of 0.05 is additional external water that is available for absorption by the SAPs to be supplied during cement hydration. From a hydration standpoint, a cement paste with a w/c ratio of 0.35 is identical to a cement paste with a base $w / c$ ratio of 0.30 and an entrained $w / c$ of 0.05 [23]. Table 3 lists the mixture design proportions of the paste samples.

All SAPs were added dry at $0.3 \%$ by weight of dry cement and pre-mixed into the cement for a homogenously distributed mixture. Water was added slowly during the first minute of mixing, and the pastes were mixed using a combination of mechanical and hand mixing for a total of time of $8 \mathrm{~min}$.

2.2.3.2 Workability of paste A miniature slump cone was fabricated according to [32] to test the workability of the paste. The cone had a height of $57 \mathrm{~mm}$, with a top and bottom diameter of $19 \mathrm{~mm}$ and $38 \mathrm{~mm}$, respectively. Cement paste was added in increments and consolidated (i.e., tamped) in three layers. Slump was defined as the difference between the original height of the miniature slump cone and the height of the paste sample once the cone was removed from the fresh paste.

2.2.3.3 Time of set Time of set was conducted according to ASTM C191 with no modifications. The time-of-set specimens were stored in a moist chamber $\left(90 \% \pm 5 \% \mathrm{RH}, 16{ }^{\circ} \mathrm{C} \pm 2{ }^{\circ} \mathrm{C}\right)$. During the first half-hour of the test, measurements were taken after the rest period in ambient laboratory conditions. Final time of set was determined once the needle left no circular impression.

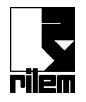

\begin{tabular}{|l|lll|}
\hline & Journal : Medium 11527 & Dispatch : $\mathbf{1 5 - 2 - 2 0 1 8}$ & Pages : $\mathbf{1 3}$ \\
Article No. : $\mathbf{1 1 6 4}$ & $\square \mathrm{LE}$ & $\square$ TYPESET \\
& MS Code : MAAS-D-17-01472 & $\cup_{\mathrm{CP}}$ & $\searrow$ DISK \\
\hline
\end{tabular}


Table 3 Sample compositions for autogenous shrinkage testing

\begin{tabular}{lllll}
\hline Sample & Base w/c & Entrained w/c & Cement $(\mathrm{g})$ & SAP $(\mathrm{g})$ \\
\hline 1 (Control) & 0.35 & - & 460 & - \\
2 (SAP A) & 0.30 & 0.05 & 460 & 1.38 \\
3 (SAP B) & 0.30 & 0.05 & 460 & 1.38 \\
\hline
\end{tabular}

\subsubsection{Autogenous shrinkage strain Autogenous} shrinkage testing was conducted according to ASTM C1698. The autogenous shrinkage device was fabricated in-house from rigid poly(vinyl chloride) (PVC) tubing for the supporting base and corrugated tubing for the sample molds. The rigidity of the PVC tubing utilized herein complies with ASTM D1785. Measurements were recorded every $30 \mathrm{~min}$ beginning at the time of final set (Day 0) for the first three hours. Subsequent measurements were taken on days 1, 2, 3, 7,14 , and 28 for all specimens. All specimens were tested in duplicate.

\section{Results}

\subsection{Physical swelling}

Figure 3 shows the time-dependent swelling of biobased SAP samples in all aqueous and ionic solutions investigated herein. Both SAPs exhibit an initially accelerated increase in absorption in both aqueous and ionic solutions. The rate of swelling decreases after $60 \mathrm{~min}$ for all SAP samples. Table 4

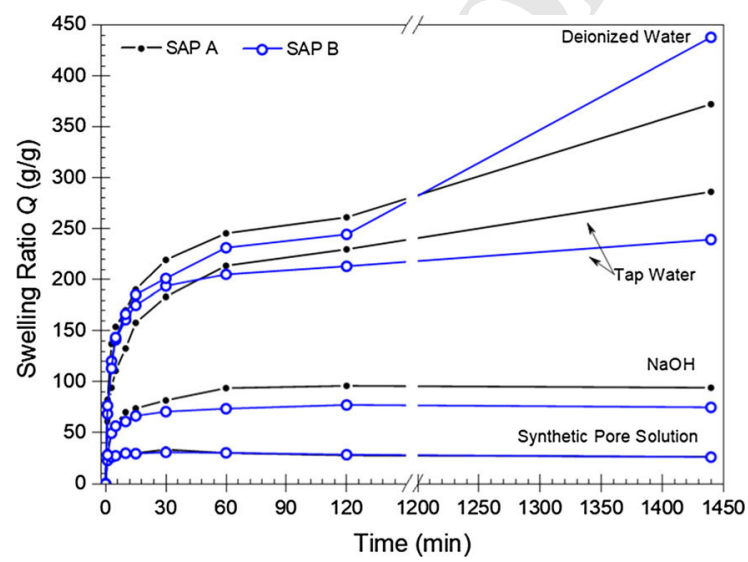

Fig. 3 Swelling ratio $(Q)$ of biobased SAPs in aqueous and ionic solutions lists the swelling ratio $(Q)$ measurements for all samples swollen in aqueous and ionic solutions at 120 min. The values represent the average of the highest swelling values from three solution absorbency trials.

All samples swollen in aqueous solutions achieved equilibrium swelling after $24 \mathrm{~h}$, whereas SAP samples swollen in $0.1 \mathrm{M} \mathrm{NaOH}$ solution and the synthetic pore solution achieved equilibrium after $60 \mathrm{~min}$ and remained at equilibrium for the duration of the test period. SAPs swollen in deionized water exhibited the highest equilibrium swelling compared to SAPs swollen in all other solutions. SAP A achieved the highest average overall swelling performance in aqueous and $\mathrm{NaOH}$ solutions, while there was no statistical difference in the swelling performances between SAP A and SAP B in the synthetic pore solution. In comparison to non-biobased, poly(acrylic acid) SAPs $[8,29,33]$ the $Q$ ratios of SAPs A and B are comparatively larger. Previously reported swelling behavior of SAP samples of similar composition to SAP A and SAP B achieved swelling ratios in deionized water equal to $56.9[\mathrm{~g} / \mathrm{g}]$ and $170.5[\mathrm{~g} / \mathrm{g}]$. Thus, SAP A and SAP B exhibited relative increases in swelling ratios compared to these SAPs of $330.1 \%$ and $53.3 \%$, respectively [33]. For swelling ratios of nonbiobased, poly(acrylic acid) SAPs in aqueous and $\mathrm{Na}^{+}$ solutions, Zhu et al. [8] reports $Q$ values as high as 89 $[\mathrm{g} / \mathrm{g}]$ in deionized water and $47.5[\mathrm{~g} / \mathrm{g}]$ in a sodium chloride solution. Krafcik et al. [29] reports $Q$ values of similar SAPs as high as 75 [g/g] and SAPs with high poly(acryclic acid content) up to $94[\mathrm{~g} / \mathrm{g}]$ in deionized water.

\subsection{DSC}

The DSC thermograms for the biobased SAPs, shown in Fig. 4, confirm no major thermal transitions within temperature ranges typical of cement hydration (20 to $65{ }^{\circ} \mathrm{C}$ ). The first transition at approximately $70{ }^{\circ} \mathrm{C}$ is a glass transition, $T_{\mathrm{g}}$, of the SAP imparted by AA [34].

\begin{tabular}{|l|lll|}
\hline & Journal : Medium 11527 & Dispatch : 15-2-2018 & Pages : 13 \\
Article No. : $\mathbf{1 1 6 4}$ & $\square$ LE & $\square$ TYPESET \\
& MS Code : MAAS-D-17-01472 & $\checkmark \mathrm{CP}$ & $\checkmark$ DISK \\
\hline
\end{tabular}


Table 4 Swelling ratio $(Q)$ of SAPs in solution $[\mathrm{g} / \mathrm{g}]$ at $120 \mathrm{~min}$ measurements

\begin{tabular}{lllll}
\hline Sample & DI & Tap & $0.1 \mathrm{M} \mathrm{NaOH}$ & Synthetic pore solution \\
\hline SAP A & $261.5 \pm 59.3$ & $230.0 \pm 59.1$ & $96.2 \pm 22.0$ & $27.9 \pm 3.7$ \\
SAP B & $244.7 \pm 57.5$ & $213.3 \pm 48.6$ & $77.4 \pm 16.0$ & $28.3 \pm 2.6$ \\
\hline
\end{tabular}

Due to the proportion of AA to $\kappa \mathrm{C}$ in the $\mathrm{SAPs}$, the $T_{\mathrm{g}}$ is shifted higher than would be seen in $\kappa \mathrm{C}$ alone. Previous studies have either reported no $T_{\mathrm{g}}$ behavior or a $T_{\mathrm{g}}$ near $45^{\circ} \mathrm{C}$ for $\kappa \mathrm{C}$, depending on water content and the sensitivity of the equipment $[35,36]$. The second transition peak near $155^{\circ} \mathrm{C}$ is due to the vaporization of tightly bound water in $\kappa \mathrm{C}[35,37]$. The third transition peak located around $202{ }^{\circ} \mathrm{C}$ is attributed to (1) the onset of the degradation of $\kappa \mathrm{C}$ in the copolymer matrix and (2) the increase in anhydride content of the AA portion of the SAP, since this transition has been observed in crosslinked poly(acrylic acid) [34, 38]. Anhydride formation is further supported by the chemical stability of anhydrous compounds, which are observable only through the first heading cycle [39] provided no degradation occurs. Upon cooling and second heating, no additional thermal transition peaks other than those previously identified were observed (data not shown).

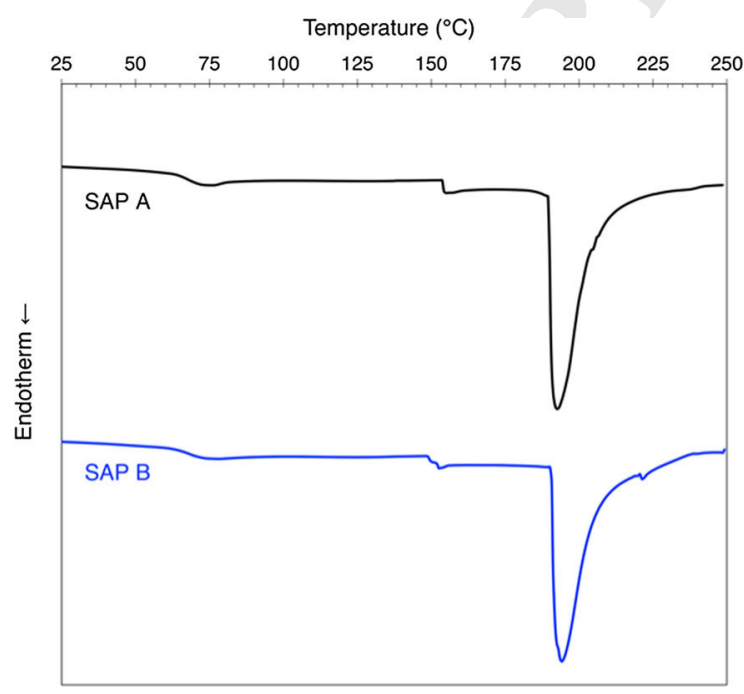

Fig. 4 DSC thermograms of biobased SAP samples

\subsection{TGA}

The TGA traces with the accompanying first derivative (DTG) curves are shown in Fig. 5 for the two biobased SAPs and the individual constituent materials, $\kappa \mathrm{C}$ and poly(acrylic acid). The decomposition of each material proceeds to final weight percentages of $9.4,12.6,16.8$, and $4.0 \%$ for SAP A, SAP B, $\kappa$ C, and crosslinked poly(acrylic acid), respectively. SAP A had a lower final weight percent compared to SAP B due to the higher proportion of AA in SAP A.

In the DTG curves, the degradation kinetics for both biobased SAPs follow similar trends with five main decomposition events represented by peaks of varying intensity. These five decomposition events are discussed individually from left to right in relation to the constituent material below. The first transition in the biobased SAPs around $270{ }^{\circ} \mathrm{C}$ are primarily attributable to the $\kappa \mathrm{C}$, with some influence from the AA. $\kappa \mathrm{C}$ exhibits a sharp decrease in mass from 240 to $260{ }^{\circ} \mathrm{C}$, which is stabilized in the biobased SAPs due to increased crosslinking density. The second and third transition in the biobased SAPs around 370 and $440{ }^{\circ} \mathrm{C}$, respectively, can be attributed to the major decomposition of AA. The fourth transition around $700{ }^{\circ} \mathrm{C}$ aligns with the final major degradation event in $\kappa \mathrm{C}$. The fifth transition around $780{ }^{\circ} \mathrm{C}$ is similarly located to the final degradation event in AA.

Overall, the thermal traces demonstrate thermal stability for these polymers for internal curing applications in cement paste, mortar, and concrete. Thermal stability ( $>90 \%$ weight) is retained at $200{ }^{\circ} \mathrm{C}$ prior to any degradation events, which, as noted, is well above typical hydration temperatures for cement-based materials.

\subsection{SEM}

Figure $6 \mathrm{a}$ shows the size distribution of SAP A particles, where a size range from tens of microns to over $200 \mu \mathrm{m}$ is evident. Ground SAP particles were

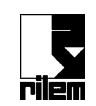

\begin{tabular}{|l|lll|}
\hline & Journal : Medium 11527 & Dispatch : 15-2-2018 & Pages : 13 \\
Article No. : $\mathbf{1 1 6 4}$ & $\square$ LE & $\square$ TYPESET \\
& MS Code : MAAS-D-17-01472 & $\checkmark \mathrm{CP}$ & $\checkmark$ DISK \\
\hline
\end{tabular}



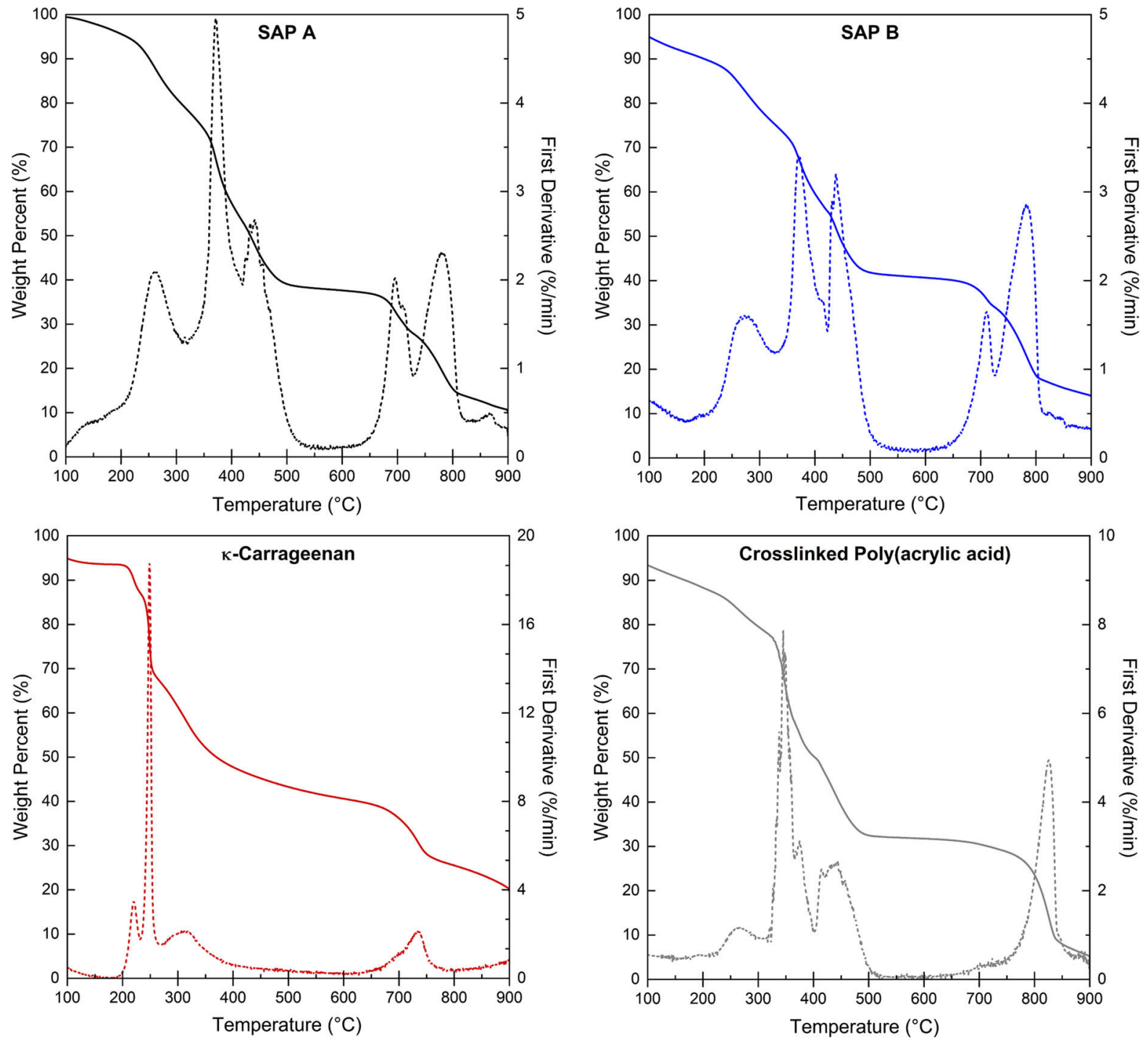

Fig. 5 TGA traces (solid line) with the accompanying first derivative (dashed line), reported in wt $\% / \mathrm{min}$, for the two SAPs (top) and the constituent materials (bottom)

passed through sieves ranging from 125 to $250 \mu \mathrm{m}$ and a random sample of SAP was obtained to limit the particle size distribution before SEM imaging. Figure $6 \mathrm{~b}$ highlights a single SAP particle in the size range of $90 \mu \mathrm{m} \times 50 \mu \mathrm{m}$. As expected, the particles exhibit an irregular shape, which can be attributed to manual grinding. This irregular morphology is similar to previously synthesized SAPs [29].

\subsection{FTIR}

The FTIR spectra for pure $\kappa \mathrm{C}$ (red) and crosslinked poly(acrylic acid) (gray), as well as SAP A (black) and SAP B (blue), are shown in Fig. 7. The major peaks for each of the constituent materials are labeled in the color of the respective spectrums to indicate origin of the functional group signal in each SAP.

In the $\kappa C$ spectrum, signals at $1220,1032,922$, and $841 \mathrm{~cm}^{-1}$ correspond to the $\mathrm{S}=\mathrm{O}$ stretch of sulfate esters, the $\mathrm{C}-\mathrm{O}$ stretch of the glycosidic linkage, the $\mathrm{C}-\mathrm{O}$ stretch of the 3,6-anhydro-D-galactose, and the

\begin{tabular}{|l|lll|}
\hline Aournal : Medium 11527 & Dispatch : 15-2-2018 & Pages : 13 \\
& Article No. : $\mathbf{1 1 6 4}$ & $\square$ LE & $\square$ TYPESET \\
& MS Code : MAAS-D-17-01472 & $\checkmark$ CP & $\checkmark$ DISK \\
\hline
\end{tabular}


Fig. 6 SEM micrographs of biobased SAP confirming a $a<200 \mu \mathrm{m}$ particle size and $\mathbf{b}$ irregular particle morphology

Fig. 7 The FTIR spectra for the two biobased SAPs (blue and black) and the constituent materials, $\mathrm{\kappa C}$ (red) and crosslinked poly(acrylic acid) (gray)
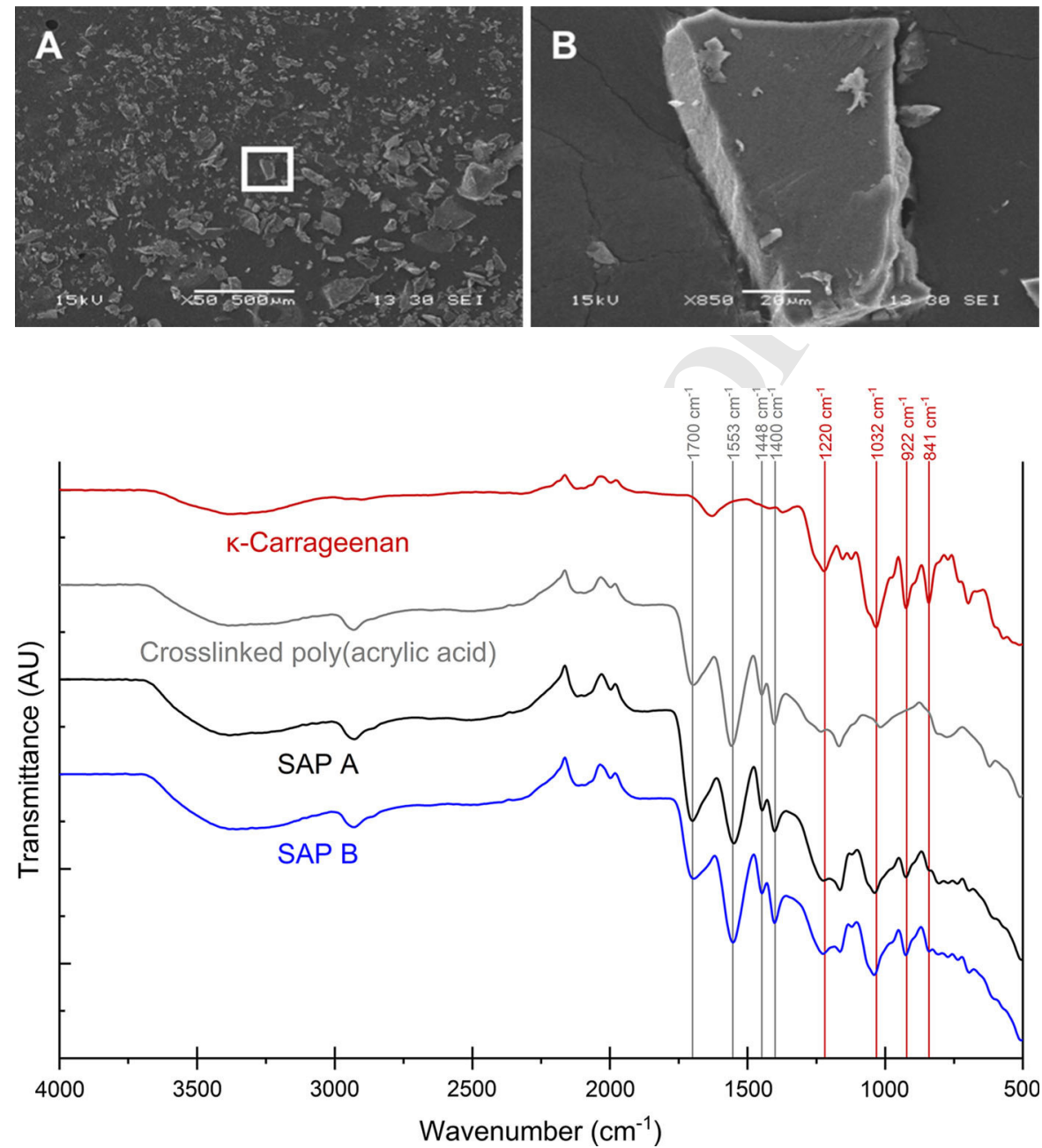

\section{$\mathrm{C}-\mathrm{O}-\mathrm{S}$ stretch of the D-galactose-4-sulfate, respec-} tively [40]. In the crosslinked poly(acrylic acid) spectrum, signals at 1700, 1553, 1448, and $1400 \mathrm{~cm}^{-1}$ correspond to the $\mathrm{C}=\mathrm{O}$ stretch of the carbonyl, the $\mathrm{COO}^{-}$stretching of the antisymmetric carboxylate ion, the $\mathrm{CH}_{2}$ stretch of the backbone, and the $\mathrm{COO}^{-}$stretching of the symmetric carboxylate ion, respectively [41]. Since the poly(acrylic acid) and SAPs were partially neutralized with $\mathrm{NaOH}$ in the synthesis process, the presence of carboxylic acid and carboxylate ions are observed in the IR spectra. These spectra indicate successful synthesis of a copolymer from $\kappa \mathrm{C}$ and $\mathrm{AA}$ by showing that the characteristic signals for each material are carried through into the resulting SAPs.

\subsection{Fresh-state properties}

As anticipated, the addition of SAP water to cement paste influenced set time and paste workability. The control paste set in $5.7 \mathrm{~h}$, while the set times of cement pastes containing SAP A and SAP B-6.7 and $7.0 \mathrm{~h}$, respectively-were delayed, as expected [31]. The workability of the cement pastes was reduced in samples that contained SAP A and SAP B. Modified miniature slump cone measurements for all samples were $12.5 \mathrm{~mm}$ for the control, and 2 and $7 \mathrm{~mm}$ for SAP A and SAP B, respectively. The paste spread did not change, and the paste was not flowable due to the low w/c ratio and a lack of superplasticizer.

\begin{tabular}{|l|lll|}
\hline & Journal : Medium 11527 & Dispatch : $\mathbf{1 5 - 2 - 2 0 1 8}$ & Pages : $\mathbf{1 3}$ \\
Article No. : $\mathbf{1 1 6 4}$ & $\square \mathrm{LE}$ & $\square$ TYPESET \\
& MS Code : MAAS-D-17-01472 & $\cup_{\mathrm{CP}}$ & $\searrow$ DISK \\
\hline
\end{tabular}


Figure 8 shows the results from the 28-day autogenous

shrinkage tests for all cement paste samples that include SAP A and SAP B, as well as the control sample. Measurements commenced immediately after final time of set starting at Day 0. All paste samples exhibit an increase in positive strain immediately after final set (Fig. 8). After the first $24 \mathrm{~h}$, however, the control sample experienced negative strain, while all samples containing the biobased SAPs experienced positive strain for the duration of the test. Negative strain indicates that the control sample was undergoing continuous self-desiccation. The control paste experienced a negative strain of $-0.99 \mathrm{~mm} / \mathrm{m}$ during the first 7 days. Positive strain observed in all cement paste samples containing the biobased SAPs show continuous expansion of the hardened paste for the first 7 days. The paste sample containing SAP A exhibited a maximum positive strain of $1.74 \mathrm{~mm} / \mathrm{m}$ on day seven of the autogenous shrinkage test. The paste containing SAP B demonstrated the highest positive strain of $2.4 \mathrm{~mm} / \mathrm{m} 7$ days after final set. The control paste continued self-desiccation through 14 days at which time the sample developed a shrinkage crack (Fig. 8).

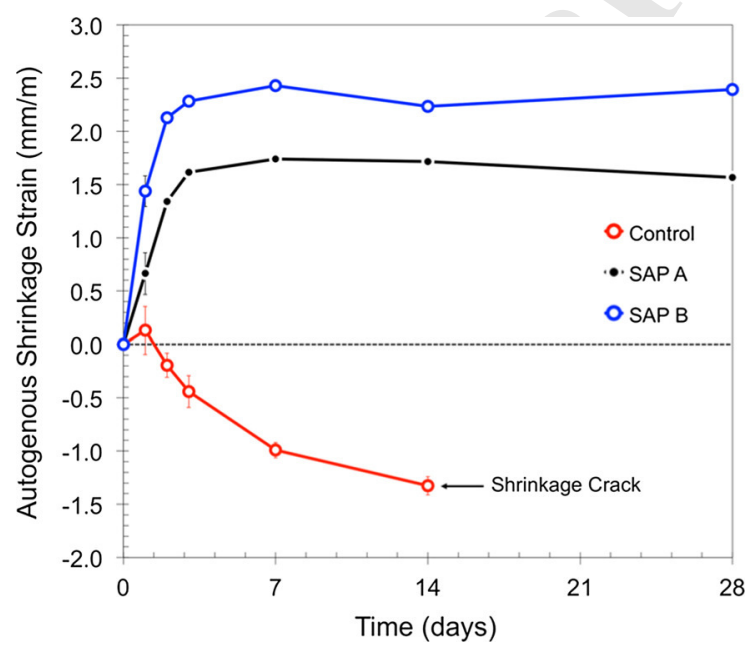

Fig. 8 Autogenous shrinkage strain measurements for control and SAP-containing cement pastes. Error bars represent \pm one standard deviation
Two biobased SAPs from $\kappa \mathrm{C}$ with varying AA content were synthesized using ambient-condition free radical polymerization. The variation in AA was used to determine the swelling capability of the SAP based on the $\kappa \mathrm{C}$ backbone. From these data, the concentration of AA does not appear to influence SAP absorption in synthetic pore solution (Fig. 3), indicating that, even at lower AA concentrations, the biobased SAPs will absorb high amounts of ionic solution. These findings suggest that the natural swelling ability of the $\kappa \mathrm{C}$, due to its intrinsic hydrophilicity, could be responsible for the swelling capacity of the biobased SAPs in pore solution. This result is an advantage of a biobased SAP, where, even with minimal AA concentrations, the $\kappa \mathrm{C}$ will allow for absorption and desorption of ionic fluid.

As shown in Fig. 3, the swelling behavior of the SAPs in pure water versus the $\mathrm{NaOH}$ solution also indicate that monovalent cations have an effect on the swelling ratio but not to the extent of the pore solution which contains mono and divalent cations $\left(\mathrm{Na}^{+}, \mathrm{K}^{+}\right.$, $\mathrm{Ca}^{2+}$ ). Previous studies have also observed a decrease in swelling capacity of SAPs in the presence of these cations due to their electrostatic attraction to the anionic functional groups within the polymer network [10, 42, 43]. More specifically, the carboxylate groups present in the SAPs are able form an ionic complexation with the $\mathrm{Ca}^{2+}$ cations, thus creating a stable polymer network and lessening the absorption capacity of the SAP [42, 44].

The swelling behavior of the SAPs in the $\mathrm{NaOH}$ and synthetic pore solutions indicate that the ion type and concentration has an effect on swelling capabilities. Even with exposure to cations (i.e., $\mathrm{Na}^{+}, \mathrm{K}^{+}, \mathrm{Ca}^{2+}$ ), the ability of the SAP to swell in ionic solutions is evident. However, the fluctuation in swelling behavior in the synthetic pore solution for all samples indicates competition between cations and the polymer's affinity to uptake water, which provides clues to the swelling kinetics of the SAP in highly alkaline environments. While the absorption of the $\mathrm{NaOH}$ and pore solution is decreased compared to the aqueous solutions, the SAPs absorb $\geq 94[\mathrm{~g} / \mathrm{g}]$ of their original weight. This good absorption may be attributed to the ability of $\kappa \mathrm{C}$ to form gels, even in the presence of $\mathrm{K}^{+}$and $\mathrm{Ca}^{2+}$ ions $[19,45,46]$.
462

463

464

465

466

467

468

469

470

471

472

473

474

475

476

477

478

479

480

481

482

483

484

485

486

487

488

489

490

491

492

493

494

495

496

497

498

499

500

501

502

503

504

505

506

507

\begin{tabular}{|l|lll|}
\hline & Journal : Medium 11527 & Dispatch : 15-2-2018 & Pages : 13 \\
Article No. : 1164 & $\square$ LE & $\square$ TYPESET \\
& MS Code : MAAS-D-17-01472 & $\checkmark \mathrm{CP}$ & $\checkmark$ DISK \\
\hline
\end{tabular}


Thermal characterization, namely DSC and TGA, was used to verify that the biobased SAPs intended for use in cement-based mixtures were stable enough to handle the heat of hydration generated during curing without substantial thermal degradation. DSC analysis elucidated that the biobased SAPs can maintain functionality at temperatures up to $200{ }^{\circ} \mathrm{C}$. TGA confirms this behavior in functionality, as it is noted that the SAP maintains $>90 \%$ of its original weight up to $200{ }^{\circ} \mathrm{C}$.

SEM images of biobased SAP particle morphology reveled irregular particle shapes and sizes, which was to be expected based on previous studies and types of SAP polymerization techniques [11, 12, 29]. Particle size distribution before sieving ranged from a few microns to over 200 microns. For this study, the effect of particle shape was not considered. Other studies have shown that SAP particle size affects the rate of absorption and maximum absorption capacity and that spherical shapes may be most effective [47] at mitigating autogenous shrinkage in cement pastes, mortars, and concrete. Researchers have also suggested that spherical shapes may promote the development of more preferred capillary pore structures [22], although care must be taken to control particle size, since the swelling capacities of SAPs have been shown to increase non-linearly as the diameter of the SAP particle is increased [47]. Thus, while mechanical alteration of the shape of the biobased SAP could be further investigated to achieve more consistent particle aspect ratios, careful control of diameter is critical to achieving maximum effectiveness.

Results of the autogenous shrinkage testing show that the addition of biobased SAP leads to a reduction in shrinkage to the point of net-positive expansion for both samples containing biobased SAP. The reference control sample exhibited a slight expansion during the initial measurements directly after the time of final set, which could be attributed to an initially high porosity that would reduce any self-desiccation stresses resulting from continuous hydration. Figure 3 illustrates that the swelling behavior of both SAP A and SAP B in the synthetic pore solution plateaued after $10 \mathrm{~min}$, quickly absorbing and retaining water that is available for cement hydration.

The high expansion values of cement pastes containing SAP A and B are higher than other expansion values reported in literature, where expansion of $1-2(\mathrm{~mm} / \mathrm{m})$ strain is expected [31]. Snoeck et al. [1] reports $0.2(\mathrm{~mm} / \mathrm{m})$ strain reduction for SAP addition of $0.22 \%$ and Jensen et al. [31] observed 0.5 $(\mathrm{mm} / \mathrm{m})$ strain for $0.3 \%$ SAP addition to cement paste. These lower values for expansion could be attributed to the utilization of additional admixtures. The cement pastes herein do not utilize any other admixtures (i.e., superplasticizers) or silica fume, since both of which exacerbates the water demand in cement pastes, mortars, and concrete, which in turn will cause a reduction in available water for the SAP to absorb. The studies referenced herein $[1,2,48]$ report the use of carboxylate superplasticizers. Though proprietary, the chemical structure of the superplasticizers is similar to acrylic/acrylamide based SAPs, through the carboxylate moieties. There is the potential for competition between the SAPs and the superplasticizers for water absorption, if these two chemicals are used in conjunction. The carboxylate moieties in the SAPs will be sterically hindered, due to the crosslinking, thus they will be less able to absorb water. To date the authors do not know of a study that reports the effects of superplasticizers or silica fume on the swelling kinetics of SAPs. Therefore, in the pure paste and SAP-containing samples, the authors would expect that the swelling ratios would be higher, leading to increased expansion values in the autogenous shrinkage testing.

Differences in autogenous shrinkage expansion values between SAP A and SAP B presented in this study could be attributed to the deswelling characteristics between the two SAPs in the presence of $\mathrm{Ca}^{2+}$ cations. It has been previously discussed that the presence of divalent cations such as $\mathrm{Ca}^{2+}$ affects the swelling behavior of SAPs. Pourjavadi et al. [10] has reported on the deswelling of non-biobased SAPs in the presence of an artificial pore solution and a cement filtrate solution. The authors showed that, while the deswelling mechanisms are not well understood, the formation of calcium carbonate in the filtrate caused rapid deswelling due to the anionic groups in the SAP [10]. Krafcik et al. [29] also indicated that the magnitude of deswelling in ionic solutions is dependent on the amount of anionic groups and their interaction with $\mathrm{Ca}^{2+}$ ions. The increased amount of $\kappa \mathrm{C}$ in SAP B would also act as a crosslinker due to the way in which the helical structures aggregate, causing the SAP to more rapidly release bound water. Thus, while the calcium ions may provide good swelling abilities of higher $\kappa \mathrm{C}$ content gels, they may also play

\begin{tabular}{|l|lll|}
\hline & Journal : Medium 11527 & Dispatch : 15-2-2018 & Pages : 13 \\
Article No. : $\mathbf{1 1 6 4}$ & $\square$ LE & $\square$ TYPESET \\
& MS Code : MAAS-D-17-01472 & $\checkmark \mathrm{CP}$ & $\checkmark$ DISK \\
\hline
\end{tabular}


606 a role in the de-swelling kinetics within paste, mortar, 607 and concrete.

Together, the swelling behavior (Fig. 3) and the autogenous shrinkage data (Fig. 8) are indicative that the biobased SAPs initially absorb and slowly release ionic pore solution during cement hydration of low w/c cement paste, effectively serving as an internal curing agent and alleviating the deleterious effects of autogenous shrinkage.

\section{Conclusions}

In this work, biobased superabsorbent polymers (SAPs) derived from kappa-carrageenan $(\kappa \mathrm{C})$ were synthesized, and their swelling behavior was characterized in tap water, deionized water, and synthetic concrete pore solution. The effect of acrylic acid monomer content on the swelling behavior was explicitly investigated, as was the time to equilibrium swelling. Results show that the ranges of equilibrium swelling ( 94-438 [g/g]) achieved by the biobased SAPs investigated herein were on par with other previously produced non-biobased synthetic SAPs and that the biobased SAPs were successful in mitigating autogenous shrinkage in a low water-to-cement $(\mathrm{w} / \mathrm{c})$ ratio cement paste. While control cement paste samples with no SAP exhibited early-age expansion and eventual cracking due to self-desiccation, the cement pastes containing $0.3 \%$ biobased SAPs by weight of cement exhibited net-positive expansion. Together, the swelling properties and autogenous shrinkage results suggest that the SAPs created in this work are promising biobased candidates for internal curing agents that are used to improve early- and lateage behavior of high-performance (i.e., low w/c) cement pastes, mortars, and concrete.

Acknowledgements This research was made possible by the Department of Civil, Environmental, and Architectural Engineering, the College of Engineering and Applied Sciences, and the Sustainable Infrastructure Materials Laboratory (SIMLab) at the University of Colorado Boulder with support from the from the National Science Foundation (Award No. CMMI-1562557). The authors would like to thank Shane Frazier for DSC data collection and Elizabeth Delesky for data collection during time-of-set testing. This work represents the views of the authors and not necessarily those of the sponsors.
Funding This study was funded in part by the US National Science Foundation (Award No. CMMI-1562557).

Compliance with ethical standards

Conflict of interest The authors declare that they have no conflict of interest.

\section{References}

1. Snoeck D, Jensen OM, De Belie N (2015) The influence of superabsorbent polymers on the autogenous shrinkage properties of cement pastes with supplementary cementitious materials. Cem Concr Res 74:59-67. https://doi.org/ 10.1016/j.cemconres.2015.03.020

2. Mechtcherine V, Gorges M, Schroefl C, Assmann A, Brameshuber W, Ribeiro AB, Cusson D, Custódio J, Da Silva EF, Ichimiya K, Igarashi SI, Klemm A, Kovler K, De Mendonça Lopes AN, Lura P, Nguyen VT, Reinhardt HW, Filho RDT, Weiss J, Wyrzykowski M, Ye G, Zhutovsky S (2014) Effect of internal curing by using superabsorbent polymers (SAP) on autogenous shrinkage and other properties of a high-performance fine-grained concrete: results of a RILEM round-robin test. Mater Struct Constr 47:541-562. https://doi.org/10.1617/s11527-013-0078-5

3. Laustsen S, Hasholt MT, Jensen OM (2015) Void structure of concrete with superabsorbent polymers and its relation to frost resistance of concrete. Mater Struct 48:357-368. https://doi.org/10.1617/s11527-013-0188-0

4. Mönnig S, Lura P (2007) Superabsorbent polymers-an AQ4 77 strength concrete. Adv Constr Mater 351-358

5. Mechtcherine V, Schröfl C, Wyrzykowski M, Gorges M, Lura P, Cusson D, Margeson J, De Belie N, Snoeck D, Ichimiya K, Igarashi SI, Falikman V, Friedrich S, Bokern J, Kara P, Marciniak A, Reinhardt HW, Sippel S, Bettencourt Ribeiro A, Custódio J, Ye G, Dong H, Weiss J (2017) Effect of superabsorbent polymers (SAP) on the freeze-thaw resistance of concrete: results of a RILEM interlaboratory study. Mater Struct Constr. https://doi.org/10.1617/s11527016-0868-7

6. Mignon A, Graulus GJ, Snoeck D, Martins J, De Belie N, Dubruel P, Van Vlierberghe S (2014) pH-sensitive superabsorbent polymers: a potential candidate material for selfhealing concrete. J Mater Sci 50:970-979. https://doi.org/ 10.1007/s10853-014-8657-6

7. Snoeck D, Van Tittelboom K, Steuperaert S, Dubruel P, De Belie N (2014) Self-healing cementitious materials by the combination of microfibres and superabsorbent polymers. J Intell Mater Syst Struct 25:13-24. https://doi.org/10.1177/ 1045389X12438623

8. Zhu Q, Barney CW, Erk KA (2015) Effect of ionic crosslinking on the swelling and mechanical response of model superabsorbent polymer hydrogels for internally cured concrete. Mater Struct 48:2261-2276. https://doi.org/ $10.1617 / \mathrm{s} 11527-014-0308-5$
679

680

681

682

683

684

685

686

687

688

689

690

691

692

693

694

695

696

697

698

699

700

701

702

703 additive to increase the freeze-thaw resistance of high 678

\begin{tabular}{|l|lll|}
\hline & Journal : Medium 11527 & Dispatch : 15-2-2018 & Pages : 13 \\
Article No. : $\mathbf{1 1 6 4}$ & $\square$ LE & $\square$ TYPESET \\
MS Code : MAAS-D-17-01472 & $\checkmark \mathrm{CP}$ & $\checkmark$ DISK \\
\hline
\end{tabular}


9. Zhang J, Wang Q, Wang A (2007) Synthesis and characterization of chitosan-g-poly(acrylic acid)/attapulgite superabsorbent composites. Carbohydr Polym 68:367-374. https://doi.org/10.1016/j.carbpol.2006.11.018

10. Pourjavadi A, Fakoorpoor SM, Hosseini P, Khaloo A (2013) Interactions between superabsorbent polymers and cementbased composites incorporating colloidal silica nanoparticles. Cem Concr Compos 37:196-204. https://doi.org/10. 1016/j.cemconcomp.2012.10.005

11. Zohuriaan-Mehr MJ, Kabiri K (2008) Superabsorbent polymer materials, Iran. Polym J 17:451-477

12. Ahmed EM (2015) Hydrogel: preparation, characterization, and applications: a review. J Adv Res 6:105-121. https:// doi.org/10.1016/j.jare.2013.07.006

13. Buchholz FL, Graham AT (1998) Modern superabsorbent polymer technology. Wiley-VCH, New York

14. Feng E, Ma G, Wu Y, Wang H, Lei Z (2014) Preparation and properties of organic-inorganic composite superabsorbent based on xanthan gum and loess. Carbohydr Polym 111:463-468. https://doi.org/10.1016/j.carbpol.2014.04. 031

15. Bhardwaj TR, Kanwar M, Lal R, Gupta A (2000) Natural gums and modified natural gums as sustained-release carriers. Drug Dev Ind Pharm 26:1025-1038. https://doi.org/ 10.1081/DDC-100100266

16. Manuhara GJ, Praseptiangga D, Riyanto RA (2016) Extraction and characterization of refined K-carrageenan of red algae [Kappaphycus alvarezii (Doty ex P.C. Silva, 1996)] originated from Karimun Jawa Islands. Aquat Procedia 7:106-111. https://doi.org/10.1016/j.aqpro.2016.07. 014

17. Rostamnia S, Doustkhah E, Baghban A, Zeynizadeh B (2016) Seaweed-derived $\kappa$-carrageenan: modified $\kappa$-carrageenan as a recyclable green catalyst in the multicomponent synthesis of aminophosphonates and polyhydroquinolines. J Appl Polym Sci 133:1-7. https://doi. org/10.1002/app.43190

18. Campo VL, Kawano DF, da Silva DB, Carvalho I (2009) Carrageenans: biological properties, chemical modifications and structural analysis-a review. Carbohydr Polym 77:167-180. https://doi.org/10.1016/j.carbpol.2009.01.020

19. Chronakis IS, Piculell L, Borgström J (1996) Rheology of kappa-carrageenan in mixtures of sodium and cesium iodide: two types of gels. Carbohydr Polym 31:215-225. https://doi.org/10.1016/S0144-8617(96)00117-8

20. Liu S, Li L (2016) Thermoreversible gelation and scaling behavior of $\mathrm{Ca}^{2+}$-induced??-carrageenan hydrogels. Food Hydrocoll 61:793-800. https://doi.org/10.1016/j.foodhyd. 2016.07.003

21. Wang F, Zhou Y, Peng B, Liu Z, Hu S (2009) Autogenous shrinkage of concrete with super-absorbent polymer. ACI Mater J 106:123-127

22. Jensen OM, Hansen PF (2001) Water-entrained cementbased materials-I. Principles and theoretical background. Cem Concr Res 31:647-654. https://doi.org/10.1016/ S0008-8846(01)00463-X

23. Bentur A, Igarashi SI, Kovler K (2001) Prevention of autogenous shrinkage in high-strength concrete by internal curing using wet lightweight aggregates. Cem Concr Res 31:1587-1591. 8846(01)00608-1
24. Mechtcherine V, Reinhardt H-W (eds) (2012) Application of superabsorbent polymers (SAP) in concrete construction: state-of-the-art report prepared by Technical Committee 225-SAP. https://doi.org/10.1007/978-94-007-2733-5

25. Weber S, Reinhardt HW (1997) A new generation of high performance concrete: concrete with autogenous curing. Adv Cem Based Mater 6:59-68. https://doi.org/10.1016/ S1065-7355(97)00009-6

26. Mechtcherine V, Snoeck D, Schröfl C, De Belie N, Klemm AJ, Ichimiya K, Moon J, Wyrzykowski M, Lura P, Toropovs N, Assmann A, Igarashi S, De La Varga I, Almeida FCR, Erk K, Ribeiro AB, Custódio J, Reinhardt HW, Falikman V (2018) Testing superabsorbent polymer (SAP) sorption properties prior to implementation in concrete: results of a RILEM Round-Robin Test. Mater Struct 51:28. https://doi.org/10.1617/s11527-018-1149-4

27. Schröfl C, Snoeck D, Mechtcherine V (2017) A review of characterisation methods for superabsorbent polymer (SAP) samples to be used in cement-based construction materials: report of the RILEM TC 260-RSC. Mater Struct Constr. https://doi.org/10.1617/s11527-017-1060-4

28. Ghods P, Isgor OB, McRae G, Miller T (2009) The effect of concrete pore solution composition on the quality of passive oxide films on black steel reinforcement. Cem Concr Compos 31:2-11. https://doi.org/10.1016/j.cemconcomp. 2008.10.003

29. Krafcik MJ, Erk KA (2016) Characterization of superabsorbent poly(sodium-acrylate acrylamide) hydrogels and influence of chemical structure on internally cured mortar. Mater Struct 49:4765-4778. https://doi.org/10.1617/ s11527-016-0823-7

30. Justs J, Wyrzykowski M, Winnefeld F, Bajare D, Lura P (2014) Influence of superabsorbent polymers on hydration of cement pastes with low water-to-binder ratio: a calorimetry study. J Therm Anal Calorim 115:425-432. https://doi.org/10.1007/s10973-013-3359-x

31. Jensen OM, Hansen PF (2002) Water-entrained cementbased materials: II. Experimental observations. Cem Concr Res 32:973-978. https://doi.org/10.1016/S0008$8846(02) 00737-8$

32. Kantro DL (1980) Influence of water-reducing admixtures on properties of cement paste-a miniature slump test. Cem Concr Aggreg. 2:95-102. doi: http://dx.doi.org/10.1520/ CCA10190J. ISSN 0149-6123

33. Pourjavadi A, Harzandi AM, Hosseinzadeh H (2004) Modified carrageenan 3. Synthesis of a novel polysaccharide-based superabsorbent hydrogel via graft copolymerization of acrylic acid onto kappa-carrageenan in air. Eur Polym J 40:1363-1370. https://doi.org/10.1016/j. eurpolymj.2004.02.016

34. Eisenberg A, Yokoyama T (1969) Dehydration kinetics and glass transition of poly(acrylic acid). J Polym Sci 7:1717-1728

35. Mitsuiki M, Yamamoto Y, Mizuno A, Motoki M (1998) Glass transition properties as a function of water content for various low-moisture galactans. J Agric Food Chem 46:3528-3534. https://doi.org/10.1021/jf9709820

36. Blanshard JMV, Lillford P, Easter S (1993) School in agricultural science (53rd: 1992: Nottingham University), the glassy state in foods, Nottingham University Press.

\begin{tabular}{|l|lll|}
\hline Journal : Medium 11527 & Dispatch : 15-2-2018 & Pages : 13 \\
Article No. : $\mathbf{1 1 6 4}$ & $\square$ LE & $\square$ TYPESET \\
MS Code : MAAS-D-17-01472 & $\checkmark_{\mathrm{CP}}$ & $\checkmark$ DISK \\
\hline
\end{tabular}


https://espace.library.uq.edu.au/view/UQ:236984\#.

WiBdrtx65fw.mendeley. Accessed 30 Nov 2017

37. Frazier SD, Srubar WV (2016) Evaporation-based method for preparing gelatin foams with aligned tubular pore structures. Mater Sci Eng C 62:467-473. https://doi.org/10. 1016/j.msec.2016.01.074

38. Carrageenan (Red Seaweed), (n.d.). http://www. cargohandbook.com/index.php/Carrageenan_(Red_ Seaweed). Accessed 16 Nov 2017

39. Shawe J, Riesen R, Widmann J, Schubnell M (2000) UserCom, Mettler Toledo 1-28

40. Chopin T, Whalen E (1993) A new and rapid method for carrageenan identification by FT IR diffuse reflectance spectroscopy directly on dried, ground algal material. Carbohydr Res 246:51-59. https://doi.org/10.1016/00086215(93)84023-Y

41. Kirwan LJ, Fawell PD, Van Bronswijk W (2003) In situ FTIR-ATR examination of poly(acrylic acid) adsorbed onto hematite at low pH. Langmuir 19:5802-5807. https://doi. org/10.1021/la027012d

42. Schröfl C, Mechtcherine V, Gorges M (2012) Relation between the molecular structure and the efficiency of superabsorbent polymers (SAP) as concrete admixture to mitigate autogenous shrinkage. Cem Concr Res 42:865-873. https://doi.org/10.1016/j.cemconres.2012.03. 011
43. Krafcik MJ, Macke ND, Erk KA (2017) Improved concrete materials with hydrogel-based internal curing agents. Gels 3:46. https://doi.org/10.3390/gels3040046

44. Plank J, Sachsenhauser B (2009) Experimental determination of the effective anionic charge density of polycarboxylate superplasticizers in cement pore solution. Cem Concr Res 39:1-5. https://doi.org/10.1016/j.cemconres. 2008.09.001

45. Therkelsen GH, Carrageenan (1993) In: Whistler RL, BeMiller JN (eds) Industrial gums: polysaccharides and their derivatives, pp 146-176

46. Kara S, Tamerler C, Pekcan Ö (2003) Cation effects on swelling of $\kappa$-carrageenan: a photon transmission study. Biopolymers 70:240-251. https://doi.org/10.1002/bip. 10467

47. Esteves LP (2011) Superabsorbent polymers: on their interaction with water and pore fluid. Cem Concr Compos 33:717-724. https://doi.org/10.1016/j.cemconcomp.2011. 04.006

48. Justs J, Wyrzykowski M, Bajare D, Lura P (2015) Internal curing by superabsorbent polymers in ultra-high performance concrete. Cem Concr Res 76:82-90. https://doi.org/ 10.1016/j.cemconres.2015.05.005

\begin{tabular}{|l|lll|}
\hline Journal : Medium 11527 & Dispatch : 15-2-2018 & Pages : 13 \\
Article No. : $\mathbf{1 1 6 4}$ & $\square$ LE & $\square$ TYPESET \\
MS Code : MAAS-D-17-01472 & $\Upsilon_{\mathrm{CP}}$ & $\checkmark$ DISK \\
\hline
\end{tabular}

